\title{
El poema "Privilegios del pobre" de Juan del Valle y Caviedes desde la perspectiva del análisis del discurso
}

\author{
The poem "Privileges of the poor" by Juan del Valle $y$ Caviedes from the \\ perspective of discourse analysis \\ O poema "Privilégios dos pobres" de Juan del Valle y Caviedes na perspectiva da \\ análise do discurso \\ Maribel Apaza-Llanos ${ }^{1}$ \\ Universidad Nacional del Altiplano, Perú \\ Ronald Callomamani-Ruiz \\ Universidad Nacional del Altiplano, Perú \\ Leydi Jacinto-Machaca \\ Universidad Nacional del Altiplano, Perú
}

DOI: https://doi.org/10.35622/j.rg.2021.02.001

Recibido 01/02/2021/ Aceptado 30/03/2021

RESUMEN. El objetivo de este trabajo fue determinar el significado del hombre pobre en el poema "Privilegios del pobre" de Juan del Valle y Caviedes desde la perspectiva del análisis del discurso. El método empleado fue la hermenéutica, para lo cual se tomó en cuenta la fenomenologia, el estructuralismo y el estudio de signos. La técnica empleada para el estudio fue el análisis del discurso poético, en la dimensión textual, enunciativa, semiótica y pragmática. En cuanto a la producción del poema "Privilegios del pobre", se evidenció los calificativos al hambre pobre, donde, Caviedes construye un sujeto cuyo punto de vista tiene matices subjetivos, sarcásticos y reflexivos. Por otro lado, el sujeto tiene la función de informar aspectos o cualidades de cómo se califica al hombre pobre, pero también, la función de aclarar al receptor que todos los calificativos al hombre pobre no son privilegios. Por eso, podemos decir que el poema expone literalmente que existe presencia del lenguaje denotativo, es decir que existen figuras literarias. Finalmente, el poema recoge todos los calificativos, podemos deducir que los semas califican la acción acaparadora del hombre pobre, queriéndose explicar sarcásticamente estas acciones en general.

PALABRAS CLAVE: Análisis, discurso, pobre, pragmática, semiótica.

ABSTRACT. The objective of this work was to determine the meaning of the poor man in the poem "Privileges of the poor" by Juan del Valle y Caviedes from the perspective of discourse analysis. The method used was hermeneutics, for which phenomenology, structuralism, and the study of signs were taken into account. The technique used for

${ }^{1}$ Correspondencia: ilujanom@est.unap.edu.pe 
the study was the analysis of poetic discourse in the textual, enunciative, semiotic, and pragmatic dimensions. Regarding the production of the poem "Privileges of the poor", the qualifiers to poor hunger were evidenced, where Caviedes constructs a subject whose point of view has subjective, sarcastic and reflective nuances. On the other hand, the subject has the function of informing aspects or qualities of how the poor man is qualified and clarifying to the receiver that all the qualifications of the poor man are not privileges. Therefore, we can say that the poem states that there is a presence of denotative language; that is, there are literary figures. Finally, the poem collects all the qualifiers; we can deduce that the seams qualify the hoarding action of the poor man, wanting to explain these actions in general sarcastically.

KEYWORDS: Analysis, discourse, poor, pragmatic, semiotic.

RESUMO. O objetivo deste trabalho foi determinar o significado do pobre no poema "Privilégios dos pobres" de Juan del Valle y Caviedes a partir da análise do discurso. O método utilizado foi a hermenêutica, para a qual foram considerados a fenomenologia, o estruturalismo e o estudo dos signos. A técnica utilizada para o estudo foi a análise do discurso poético, na dimensão textual, enunciativa, semiótica e pragmática. No que diz respeito à produção do poema "Privilégios dos pobres", evidenciaram-se os qualificativos para a fome dos pobres, onde Caviedes constrói um sujeito cujo ponto de vista possui nuances subjetivas, sarcásticas e reflexivas. Por outro lado, o sujeito tem a função de informar aspectos ou qualidades de como o pobre é qualificado, mas também, a função de esclarecer ao receptor que todas as qualificações do pobre não são privilégios. Portanto, podemos dizer que o poema afirma literalmente que há presença da linguagem denotativa, ou seja, há figuras literárias. Por fim, o poema reúne todos os qualificadores, podemos deduzir que os semas qualificam a ação de açambarcamento do pobre, querendo explicar sarcasticamente essas ações em geral.

PALAVRAS CHAVE: Análise, discurso, pobre, pragmático, semiótico.

\section{INTRODUCCIÓN}

Privilegios del pobre es un poema del autor Juan del Valle y Caviedes (Porcuna, España, 1652 - Lima, 1698). Escritor peruano de origen español. Caviedes ha sido considerado esencialmente como un poeta satírico. Habida cuenta de la mordacidad de sus versos, pero también en función de su leyenda biográfica; más frecuente ha sido su asimilación con Quevedo (Martin, 2017).

El aspecto de la pobreza se refleja claramente en la obra de Caviedes que puede ser definida de diferentes formas. La pobreza vinculada a la clase social comúnmente hace referencia a las condiciones sociales de los pobres. La idea de "clase social" identifica la posición socioeconómica con el estatus socioeconómico. Para esta concepción, los roles sociales y ocupacionales son constitutivos de la noción de clase. El concepto de clase es utilizado tanto como un medio para conceptualizar la posición de los pobres, así como de referencia para la investigación empírica sobre los impactos distributivos de las políticas públicas (Spicker, 1958). 
Pobreza absoluta. Se define respecto a una cantidad de dinero necesario para satisfacer necesidades básicas (comida, vestido, etc.) sin incorporar conceptos de calidad de vida (Galindo \& Ríos, 2015).

También la pobreza relativa se define respecto a un estándar de vida dado en una sociedad. Se determina al comparar un individuo con el estatus económico de otros miembros de la sociedad (Galindo \& Ríos, 2015). Así, la pobreza relativa puede aumentar aún si el estándar de vida de los pobres aumenta en términos reales (Bourguignon, 2004).

Por otro lado, la pobreza en términos monetarios significa la carencia de ingresos, que corresponde al costo de una canasta de consumo básico, para la cual el umbral de ingresos apenas alcanza para satisfacer los requerimientos nutricionales básicos de una familia. Por lo tanto, revela sólo parcialmente el impacto de la disponibilidad monetaria sobre el bienestar, aunque se supone que el ingreso permite satisfacer las necesidades fundamentales (Romero, 2000).

Sin embargo, en la poesía de Juan del Valle y Caviedes tiene una característica muy peculiar de definir o identificar a la pobreza o al hombre pobre. Es decir, desde la perspectiva sociológica o antropológica. Por otro lado, el orden establecido en la colonia se basó en una clara distinción social donde, se diferencia dos grupos: uno dominante (los colonizadores) y otro sometido (los colonizados). Es decir, los españoles y sus hijos nacidos en América, tenían el poder económico y los indígenas, negros eran quienes debían trabajar para proveer a la colonia. No obstante, en uno y otro grupo existían a su vez relaciones jerárquicas según el origen y el color de piel de las personas (Patrucco, 1997).

Las obras de la época colonial han sido estudiadas desde distintas perspectivas, mas no desde la perspectiva del análisis del discurso. En ese sentido, este trabajo tuvo como objetivo analizar e interpretar desde la perspectiva del análisis de discurso el poema "Privilegios del pobre" de Juan Del Valle Caviedes.

\section{MÉTODO}

El método que se empleó para analizar la obra fue la hermenéutica, en ella se tomó en cuenta el aspecto fenomenológico basada en la eidética y heurística considerado por Sartre (citado por Santiesteban, 2015), Husserl (citado por Bolio, 2012), Heidegger (citado por Quesada, 2013) y Merleau (citado por Perruchoud, 2017); asimismo se consideró el estructuralismo, basado en el sector lingüístico y antropológico. En lo lingüístico Saussure, 2004 (citado por Cárdenas, 2017) y en lo antropológico Lévi Strauss (citado por Cubi, 1967), Leach (citado por Ringuelet, 2013), Barthes (citado por Fernández, 2006) y Eco (citado por Miquel, 1986).

Además, se tomó en cuenta el estudio de los signos de Saussure (citado por Vitale, 2004), Jakobson (citado por Sanz, 2012) y Peirce (citado por Magariños, 1983). Se fundamenta 
que el estructuralismo epistemológicamente idealista, es un método que desde la antropología y la lingüística realizan un análisis de la verdad del texto, como una reflexión racional independiente, en la línea del positivismo lógico. Considerando la "obra" únicamente como un "objeto", dejando de lado la expresividad y todo juicio de valor.

La técnica empleada para el estudio del poema fue el análisis del discurso poético basada en los presupuestos teóricos de Van Dijk (citado por Meersohn, 2005) y en el modelo de interpretación literaria propuesta por Núñez (2019). Desde la perspectiva del análisis de discurso, se propone interpretar el poema a través de cuatro dimensiones: textual, enunciativa, semiótica y pragmática. A continuación, se exponen cada una de éstas.

\section{a) Dimensión textual}

Según Halliday y Hassan (1976) (citado por Marimón, 2008) el texto es la unidad lingüística comunicativa fundamental, el cual es el producto de la actividad verbal humana. Posee siempre un carácter social el cual está caracterizada por su cierre semántico y comunicativo, así como por su coherencia profunda y superficial, debido a la intención comunicativa del hablante de crear un texto íntegro y a su estructuración mediante dos conjuntos de reglas: las propias del nivel textual y las del sistema de la lengua.

Las propiedades del texto son las siguientes; adecuación, coherencia, cohesión, corrección y estilística; las cuales son una serie de principios que deben cumplir los discursos o textos para que la comunicación entre emisor quien es la persona hablante y el destinatario quien es el que recibe el mensaje tengan una comunicación muy bien construida (Bernández, 1994).

La cohesión está relacionada con la manera de cómo se conectan los componentes que conforman la estructura superficial del texto; es decir, las palabras que se oyen o se ven. Es por eso que consideran el término cohesión, como las relaciones conectivas de significación que se dan entre sí en la estructura de un texto, que permiten definirlo como tal, diferenciar entre una producción textual de otra que no lo es (Calsamiglia \& Tusón, 1999).

Núñez (2019) afirma que esta categoría permite describir la textura del discurso poético, es decir, el entramado textual. Es por eso que el poema se estructura en función de unidades textuales en donde se considera, enunciados y estrofas. De modo que un poema, en su totalidad, es considerado como un texto. En donde se realizan el análisis de los mecanismos de cohesión y análisis de la coherencia.

\section{b) Dimensión enunciativa}

El enunciado es la unidad básica de gramática básica textual y se define como la unidad mínima de comunicación en interpretación verbal, es decir es el mínimo acto de habla. Para que exista enunciado debe existir una comunicación real, es decir, que haya un 
hablante, un oyente, un mensaje comunicado en un contexto. Por lo tanto el enunciado es una unidad de realización, no una enunciación realización abstracta (Fuentes, 2007).

Ascombre y Ducrot 1976 (citado por González \& Franco, 2015) definen al enunciado como la actividad del lenguaje ejercida por quien habla, en el momento preciso en el que habla, pero también por quien escucha y el momento en el que escucha.

Por otro lado, Di Tullio (2012) define los enunciados como unidades del discurso, que se caracterizan por su independencia gramatical y de entonación, puesto que no forman parte de una unidad más amplia.

El enunciado es una unidad de comunicación, o sea, una unidad pragmática. En tanto que unidad de comunicación, debe tener sentido completo dentro de la situación en que se produce (significación contextual). El enunciado se caracteriza porque está delimitado por pausas mayores (por ejemplo, la del punto y el silencio). Tiene capacidad comunicativa por sí mismo y sentido completo dentro de un texto y está envuelto por una curva de entonación determinada.

El enunciado es la unidad mínima de comunicación: producción lingüística concreta asumida por un hablante particular, con una intención específica y en circunstancias espaciales y temporales determinadas. Por lo tanto, es irrepetible (Pérez, 2015).

\section{c) Dimensión semiótica}

Flores (2016, como se citó en Valdez, 2018) afirma que la semiótica estudia los signos en relación con la sociedad donde se produce, con la cultura y con el pensamiento del cual es parte.

Al respecto, Martin (2000, como se citó en Valdez, 2018) ofrece una explicación sobre el término y su ámbito de uso y afirma que la semiótica es la teoría de la significación, es decir, de la generación o producción de significado. En otras palabras, lo que interesa al semiótico es lo que hace que una expresión sea significativa, su significado y lo que lo precede en un nivel más profundo para dar como resultado la manifestación de significado. De manera que la teoría semiótica se basa en la creencia de que el significado no es inherente a los objetos, que no significan por sí mismos, sino que el significado lo construye un observador competente, un sujeto, capaz de dar "forma" a los objetos.

\section{d) Dimensión pragmática}

Según Leech (1983, citado por Sentis, 1999) afirma que en sus inicios la pragmática era considerada una especie de basurero en el cual se depositaban todos los aspectos del lenguaje no reducibles a los modelos de la semántica o la sintaxis, fueran estos de inspiración estructuralista o generativa. Así concebida, era pues una disciplina que debía hacerse cargo de los elementos residuales de la semántica y de la sintaxis. Diversos avances ocurridos al interior de la lingüística norteamericana, a partir de la segunda 
mitad de la década de los ochenta, contribuyeron a introducir un paulatino cambio de perspectiva para la pragmática.

Según Morris (1985, como se citó en Lada, 2001) la dimensión pragmática es entendida como la ciencia de la relación de los signos con sus intérpretes. Por otro lado, Austin (1962 citado por González y Franco, 2015) afirma que la pragmática es el estudio del lenguaje en tanto la acción que se hace al decir algo, o cómo hacer cosas con palabras. Del mismo modo se pone de manifiesto que el lenguaje es también una forma de conducta y, de este modo, se cuenta entre los trabajos no lingüísticos fundacionales de la Pragmática.

La pragmática es la disciplina lingüística que estudia cómo los seres hablantes interpretamos enunciados en contextos. La pragmática estudia el lenguaje en función a la comunicación, lo que equivale a decir que se ocupa entre el lenguaje y el hablante, o por lo menos de algún aspecto de esta relación (Reyes, 1990).

Según Rico (1988) la pragmática tiene característica en su orientación hacia los textos con intercambio verbal.

Por otro lado, Gutiérrez (2015) afirma que la pragmática es una disciplina que estudia, respectivamente, la organización del significado y del sentido en la lengua.

\title{
e) Corpus de studio
}

\section{Poema los privilegios del pobre - Juan del Valle y Caviedes}

\author{
El pobre: Es tonto, si calla; \\ y si habla: Un majadero \\ si sabe, es hablador \\ y si es afable:Un embustero, \\ si es cortés: Entrometido \\ y cuando no sufre: Soberbio \\ cobarde, cuando es humilde \\ y loco cuando es resuelto. \\ Si es valiente: Temerario \\ y presumido si es discreto.
}

Adulador si obedece

y si se excusa: Grosero

Si pretende es atrevido;

si merece es sin aprecio

su nobleza es nada vista

y su gala: Sin aseo; 
si trabaja codicioso

y por el contrario extremo

un perdido si descansa...

!Miren si son privilegios!

\section{RESULTADOS Y DISCUSIONES}

\section{Dimensión textual}

En el poema se observan cinco enunciados claramente identificables, tal como se presenta en la Tabla 1. Los cuales están relacionados de distintas formas, y en conjunto forman la unidad mayor (texto).

Tabla 1

Enunciados del poema

\section{Enunciados del poema "Los privilegios del pobre"}

1. El pobre: Es tonto, si calla;/si habla: Un majadero/si sabe, es hablador/y si es afable: Un embustero, /si es cortés: Entrometido/y cuando no sufre: Soberbio/cobarde, cuando es humilde/y loco cuando es resuelto. /

2. Si es valiente: Temerario/y presumido si es discreto.

3. Adulador si obedece/y si se excusa: Grosero.

4. Si pretende es atrevido;/si merece es sin aprecio/su nobleza es nada vista/y su gala: Sin aseo;/si trabaja codicioso/y por el contrario extremo/un perdido si descansa...

5. ! Miren si son privilegios!

Fuente: elaboración propia

En el poema de estudio podemos identificar cinco enunciados, así como se muestra en la tabla 1. Los mecanismos cohesivos identificados son de carácter semántico, en algunos casos se presenta las figuras literarias de; polisíndeton, epíteto.

En el primer enunciado se evidencia la figura literaria epíteto, pues caracteriza una cualidad inherente del ser. "El pobre: Es tonto, si calla;/si habla: Un majadero/si sabe, es hablador/y si es afable: Un embustero, /si es cortés: Entrometido/y cuando no sufre: Soberbio/cobarde, cuando es humilde/y loco cuando es resuelto.

A manera de ilustración, en el segundo enunciado, presenta la figura literaria de epíteto, a su vez, existe la palabra cohesiva, en donde es el relativo "y". Su función es relacionar la acción "Si es valiente: Temerario" y el agente "presumido si es discreto". Lo mismo 
sucede con el tercer enunciado. "Adulador si obedece" y el agente "si se excusa: Grosero". Al observar el cuarto enunciado se ve la figura literaria de polisíndeton ya que existe el uso reiterado de conjunciones para aumentar la fuerza expresiva del poema. Así mismo, existe repetición diseminada ya que hay repetición de palabras como hilo conductor del poema "y" ("Si pretende es atrevido; / si merece es sin aprecio / su nobleza es nada vista/y su gala: Sin aseo;/si trabaja codicioso/y por el contrario extremo / un perdido si descansa..."). Finalmente, el último enunciado constituye una especie de conclusión general del poema. El concepto que se impulsa es de tipo acción ("Miren si son privilegios") pues aquí nos trata de decir que los pobres somos "privilegiados" pero es una manera de decir, ya que el autor nos da a entender que es todo lo contrario que somos mal vistos por una sociedad llena de malas personas, que nos ven mal a los humildes que se esfuerzan por salir adelante sin hacerle daño a nadie.

\section{Dimensión enunciativa}

El deíctico "es" permite determinar la voz que habla. Esta voz se configura en segunda persona gramatical, cuyo punto de vista es subjetivo. Lo que se quiere decir es que el autor (sujeto empírico) describe cómo se entiende las acciones del hombre pobre frente a una sociedad que juzga. El pobre: Es tonto, si calla;/si habla: Un majadero/si sabe, es hablador/y si es afable: Un embustero, /si es cortés: Entrometido/y cuando no sufre: Soberbio/cobarde, cuando es humilde/ y loco cuando es resuelto. /. Por lo tanto, puede decirse que estas afirmaciones, las percepciones, las reflexiones que se expresan en el poema forman parte de la realidad. Por ende, se estaría hablando del desdoblamiento del autor, o sea, éste es representado en el texto por el hablante lírico. A esta afirmación corrobora la perspectiva en primera persona gramatical en la que se enuncia el poema.

Sin embargo, en el poema habría dos voces: la del autor y la del hablante lírico. El autor se muestra subjetivo, reflexivo frente a su discurso y a la realidad que percibe. Se construye a sí mismo como alguien que reflexiona sobre la vida y los calificativos hacia el hombre pobre. Para lograr tal propósito, el hablante lírico informa sobre su condición. El hablante lírico habla sobre él, y sus percepciones. Pues el hablante lírico opta la posición reflexiva al enunciar el discurso poético. ¿Para quién enuncia el hablante lírico?, ¿a quién se dirige? En el poema está explícito a quien dirige el poema. El enunciado producido tiene un destinatario fijo y/o configurado, aunque da la sensación de estar hablando en función de su propia condición usando el sarcasmo como recurso para expresar la realidad. 


\section{Dimensión semiótica}

Tabla 2

Análisis dimensión semiótica

\begin{tabular}{|c|c|}
\hline Lexema & Semas que Genera \\
\hline Pobre: & /carencia/ /escases/ /sucio/ / necesidad//insolvente/ \\
\hline Tonto: & /incapaz//iletrado//incoherente/ \\
\hline Majadero: & /necio/ /idiota/ \\
\hline Afable: & /amable/ /atento/ / cariñoso/ / apacible/ \\
\hline $\begin{array}{l}\text { Embustero: } \\
\text { Cortés: }\end{array}$ & $\begin{array}{l}\text { /falso/ / mentiroso/ / traidor/ / hipócrita/ } \\
\text { /respetuoso/ / apacible/ }\end{array}$ \\
\hline Entrometido: & /curioso/ /indiscreto/ / chismoso/ \\
\hline Soberbio: & $\begin{array}{l}\text { /fuerte/ /malévolo/ /altanero/ /orgulloso/ /arrogante/ } \\
\text { /engreído/ }\end{array}$ \\
\hline Cobarde: & /miedoso/ / temeroso/ / timido/ \\
\hline $\begin{array}{l}\text { Humilde: } \\
\text { Loco: }\end{array}$ & $\begin{array}{l}\text { /sumiso/ /obediente/ / tranquilo/ / conformista/ } \\
\text { /desequilibrado/ /maniático/ /imprudente/ }\end{array}$ \\
\hline Valiente: & /coraje/ /valeroso/ /varonil/ /atrevido/ \\
\hline Presumido: & /creido/ /vanidoso/ \\
\hline Discreto: & /callado/ / silencioso/ / reservado/ \\
\hline Temerario: & /salvaje/ /feroz/ / fuerte/ / cruel/ \\
\hline Adulador: & /elogioso/ /infame/ /alabador/ \\
\hline Grosero: & /vulgar/ / malcriado/ / tosco/ \\
\hline Atrevido: & /valiente/ /fuerza/ \\
\hline Sin aseo: & /sucio/ / piojoso/ / harapiento/ / andrajoso/ \\
\hline Trabajar: & /dinero/ / cansancio/ / digno/ \\
\hline Codicioso: & /envidioso/ /acaparador/ /ambicioso/ \\
\hline
\end{tabular}

Fuente: elaboración propia

El lexema "pobre" genera los semas: /carencia/ /escases/ /sucio/ / necesidad/ /insolvente/. El lexema "tonto": /incapaz/ /iletrado//incoherente/. El lexema "majadero" genera los semas: /necio/ /idiota/. El lexema "afable" origina los semas: /amable/ / atento/ / cariñoso/ /apacible/. El lexema "embustero" produce los semas: /falso/ /mentiroso/ / traidor/ /hipócrita/. El lexema "cortés" muestra: /respetuoso/ /apacible/. El lexema "entrometido" genera los semas: /curioso/ /indiscreto/ /chismoso/. El lexema "soberbio" origina los semas: /fuerte/ /malévolo/ /altanero/ /orgulloso/ /arrogante/ /engreído/. 
Estos semas constituyen el calificativo que se les atribuye al hombre pobre, el cual nos hace entender que el pobre se caracteriza por ser menospreciado por la clase alta y atribuyéndole a sus actitudes calificativos de menosprecio y falsedad.

Tabla 3

Análisis dimensión semiótica: orientación de lexemas

\begin{tabular}{ll}
\hline Lexema & Semas que genera \\
\hline Cobarde & /miedoso/ / temeroso/ / tímido/ \\
Humilde & /sumiso/ / obediente/ / tranquilo/ / conformista/ \\
Loco & /desequilibrado/ / maniático/ /imprudente/ \\
Valiente & /coraje/ / valeroso/ / varonil/ /atrevido/ \\
presumido & /creído/ / vanidoso/ \\
Discreto & /callado/ / silencioso/ / reservado/ \\
Resuelto & /atrevido/ /decisivo/ \\
Temerario & /tosco/ bestia/malévolo \\
\hline
\end{tabular}

Fuente: elaboración propia

En este segundo bloque los lexemas y semas se han orientado en dos grupos:

Grupo 1: "cobarde" "humilde" "discreto"

Grupo 2: "valiente" "loco" "resuelto" "temerario"

Si nos podemos dar cuenta en estos dos grupos existe una oposición de semas mencionados anteriormente.

Ahora bien, podemos deducir que el primer grupo de lexemas ("cobarde" "humilde" "discreto") se cataloga al hombre pobre como ser truncado y sin aspiraciones en la vida. Por otro lado, en el segundo grupo ("valiente" "temerario" "loco" "resuelto" podemos afirmar que el hombre pobre es capaz de afrontar realidades distintas sin importar el desprecio de la sociedad.

En este segundo bloque de lexemas, los semas que genera nuevamente constituyen el calificativo que se le atribuye al hombre pobre, el cual nos hace entender que cualquier actitud tomada por el pobre siempre será rechazada y menospreciada a pesar del esfuerzo del hombre pobre. 
Tabla 4

Análisis dimensión semiótica

\section{Lexema Semas que genera}

\begin{tabular}{ll}
\hline Adulador & /elogioso/ /infame/ /alabador/ \\
Grosero & /vulgar/ / malcriado/ / tosco/ \\
Atrevido & /valiente/ /fuerza/ \\
sin aseo & /sucio/ / piojoso/ / harapiento/ /andrajoso/
\end{tabular}

Fuente: elaboración propia

En los semas del tercer bloque se resalta las características y cualidades, entendidas como esfuerzos poco considerados por la sociedad, a pesar que el hombre pobre muestre esfuerzos de superación.

Tabla 5

Análisis dimensión semiótica: última estrofa

\section{Lexema}

Semas que genera

\begin{tabular}{ll}
\hline Trabajar & /dinero/ / cansancio/ /digno/ \\
Codicioso & /envidioso/ / acaparador/ /ambicioso/ \\
Perdido & /complejo/ / sin orientación/ \\
Privilegio & /preferencia/ / suerte/ /gozo/ \\
\hline
\end{tabular}

Fuente: elaboración propia

De acuerdo con la última estrofa podemos deducir que los semas califican la acción acaparadora del hombre pobre sin orientación, queriéndose explicar sarcásticamente estas acciones en general.

\section{Dimensión pragmática}

El contexto del autor y los actos de habla

En el poema se han encontrado cinco enunciados. Los cuales a nivel locutivo explican las características y cualidades que tiene el pobre dentro de la sociedad. Las cualidades del pobre que se pueden apreciar en el poema son: 
Tabla 6

Análisis dimensión pragmática: cualidades del pobre

El pobre es:

$\begin{array}{ll}\text { Un tonto } & \text { (si calla) } \\ \text { un temerario } & \text { (si es valiente) } \\ \text { Adulador } & \text { (si es obedece) } \\ \text { atrevido } & \text { (si pretende) } \\ \text { un perdido } & \text { (si descansa) }\end{array}$

Fuente: elaboración propia

A nivel locutivo, la función del sujeto lírico es informar aspectos o cualidades de los que se descifra del hombre pobre por ello es considerado como un tonto si calla. Así mismo en el segundo enunciado se agrega que el hombre pobre es temerario si es valiente. Del mismo modo los demás párrafos describen las cualidades del hombre pobre como adulador, atrevido, un perdido, ahí nos podremos dar cuenta si todo ello no es un privilegio para el hombre pobre.

A nivel perlocutivo, la función del sujeto lírico es aclarar al receptor que todos los calificativos hacia el hombre pobre no son privilegios.

A nivel ilocutivo, el poema expone literalmente que no existe presencia de lenguajes connotativos más bien son denotativas por ello se puede decir que existe la figura literaria de comparación o símil que puede manifestarse en el último verso de poema. Esto implicaría que ser pobre tiene muchos atributos, al pobre se le puede llamar con distintos calificativos de menosprecio.

El poema privilegios del pobre se escribió porque el sujeto empírico pasó tales sufrimientos en la vida, recibiendo el desprecio de la sociedad en los trabajos explotadores mineros, por la enfermedad que le sumergió, por ello escribió para expresar todos los sufrimientos que pasa el hombre pobre.

En el poema presenta antivalores como son: desprecio, discriminación, burla, deshonestidad.

\section{CONCLUSIONES}

El poema "Privilegios del pobre" de Juan del Valle y Caviedes muestra acepciones del hombre pobre, en una sociedad que divide a las personas en clases sociales donde el hombre pobre es catalogado como un tonto, majadero, embustero, adulador, entrometido, soberbio, etc. Estos calificativos indican que su nobleza es nada vista y más por el contrario cualquier esfuerzo también será calificado negativamente. 
Al realizar el análisis del poema en la dimensión textual se pudo encontrar cinco enunciados, los cuales fueron analizados utilizando diversos elementos cohesivos, donde nos da a entender que el hombre pobre por más que se esfuerce por salir adelante siempre será menospreciado por la sociedad.

En la dimensión enunciativa, Juan del Valle y Caviedes se muestra subjetivo frente a su discurso y a la realidad que percibe, lo que se quiere decir es que el autor quien es el sujeto empírico describe cómo se entiende las acciones del hombre pobre frente a una sociedad que juzga. El hablante lírico quien es un personaje que el autor crea para que habla sobre él y sus percepciones, en el poema opta la posición reflexiva al enunciar el discurso poético.

En cuanto al poema privilegios del pobre se puede concretar que en todo el análisis de la dimensión semiótica los semas constituyen el calificativo al hombre pobre, el cual nos hace entender que el hombre pobre es menospreciado, que su actitud siempre sea rechazada por la clase alta, a pesar de que el hombre muestre esfuerzos. Del mismo modo en la última estrofa el autor manifiesta sarcásticamente si todo lo dicho en el poema, son privilegios.

El poema manifiesta diversos antivalores, como: menosprecio que recibe el hombre pobre por parte de la clase alta, la discriminación constante por la sociedad, lo cual hace que el hombre pobre sea rechazado a pesar de los esfuerzos de superación, por los trabajos que haga este.

\section{REFERENCIAS}

Bernández, E. (1994). La coherencia textual como autorregulación en el proceso comunicativo. Boletín de Filología, 34(1), ág. 9-32.

Bolio, A. (2012). Crítica de las ciencia positivas. Redalyc, 20-29.

Bourguignon, F. (2004). The Poverty-Growth-Inequality Triangle.

Calsamiglia, H., \& Tusón, A. (1999). Las cosas del decir. Manual de análisis del discurso. En Revista Electrónica Educare (Ariel, Vol. 19, Número 1). https://doi.org/10.15359/ree.19-1.21

Cárdenas, V. (2017). Releyendo a Ferdinand de Saussure: El signo lingüistico. En Cuadernos de la Facultad de Humanidades y Ciencias Sociales Universidad Nacional de Jujuy (Números 0327-1471).

Cubi, M. (1967). Claude Lévi Strauss antropología estructural (Paidos).

Di Tullio, Á. (2012). Gramatica Español Para Maestros Uruguay.pdf (pp. 15-43).

Fernández, C. (2006). Roland Barthes y el análisis del discurso. Empiria, 11-35.

Fuentes, C. (2007). Sintaxis del enunciado: los complementos periféricos. Arco Libros.

Galindo, M., \& Ríos, V. (2015). Pobreza en serie de Estudios Económicos. México ¿Como vamos?. México D.F., 1, 1-10.

González, Z., \& Franco, L. (2015). La pragmática, el análisis del discurso sociocultural y la narrativa en la enseñanza de la lengua inglesa. EduSol, 15(51), 107-105. 
Lada, U. (2001). La dimensión pragmática del signo literario. Estudios filológicos, 36, 61-70. https://doi.org/10.4067/S0071-17132001003600004

Magariños, J. (1983). El signo. Las fuentes teóricas de la semiología (Librería H).

Marimón, C. (2008). Análisis de textos en español (Universidad de Alicante (ed.); Alicante).

Martin, A. (2017). Juan del Valle y Caviedes en los Márgenes de la Ciudad Letrada: Estrategias«INTRATEXTUALES" de Autolegislación. Revista de estudios áureos.

Meersohn, C. (2005). Introducción a Teun Van Dijk : Análisis de Discurso. Cinta moebio, 24, 288-302.

Miquel, R. (1986). Introducción a la semiótica (Editorial).

Núñez, J. (2019). El poema XI de Alberto Mostajo a la luz del Análisis del Discurso. Revista Innova Educación, 1 Num 2, 15. https://doi.org/10.35622/j.rie.2019.02.008

Ordóñez, S. (2015). De pragmática y semántica. 17-405.

Patrucco, S. (1997). El Peru virreinal: sociedad, economía y arte.

Pérez, L. (2015). Enunciado y oración relaciones entre oraciones.

Perruchoud, S. (2017). La fenomenología según Merleau-Ponty: un camino descendente. Revista de Filosofía (Madrid), 42(1), 60-75. https://doi.org/10.5209/resf.55447

Quesada, J. (2013). Julio Quesada Martín| Heidegger: la decapitación de la fenomenología y el totalitarismo nazi. 713 Heidegger: la decapitación de la fenomenologia y el totalitarismo nazi. Eikasia, 715-735.

Reyes, G. (1990). La pragmática linguïstica : el estudio del uso del lenguaje (1 ed). Montesinos.

Rico, F. (1988). Pragmática y construcción literaria.

Ringuelet, R. (2013). Temas y problemas en Antropología Social (Edulp).

Romero, A. (2000). El mundo de la pobreza. 1(2), 35-59.

Santiesteban, L. (2015). Jean Paul Sartre y la fenomenología. Graffylia, 87-93.

Sanz, R. (2012). Epistemología e historia de la ciencia. Universidad Nacional de Córdoba, 15, 2-320.

Sentis, F. (1999). Dimeciones Pragmáticas.

Spicker, P. (1958). Definiciones De Pobreza: Doce grupos de significados.

Valdez, R. (2018). Elementos de semiótica y semiología.

Vitale, A. (2004). El estudio de los signos. Peirce y Saussure. En El estudio de los signos. Peirce y Saussure (Eudeba, pp. 7-45). 